\title{
Narrar é resistir: impasses de representação narrativa em João Guimarães Rosa no fim dos anos 1940
}

\author{
To narrate is to resist: narrative representational impasses in \\ João Guimarães Rosa in the late 1940's
}

\section{Guilherme Mazzafera e Silva Vilhena ${ }^{1}$}

Faculdade de Filosofia, Letras e Ciências Humanas da Universidade de São Paulo - FFLCH - USP - Brasil

\begin{abstract}
Resumo: O ensaio procura flagrar o surgimento de um segundo "momento de escritura" na obra Guimarães Rosa, delineado por um conjunto de textos publicados em periódicos entre Sagarana (1946) e os livros de 1956, Corpo de baile e Grande sertão: veredas. A partir da análise de uma importante carta do autor e de um dos textos síntese do período, "Com o vaqueiro Mariano", procuramos compreender as linhas de força de uma nova inflexão da literatura rosiana caracterizada pelo combate aos problemas da "deficiência representativa" imanente ao contexto literário brasileiro e internacional e pela constituição progressiva de uma voz narrativa em primeira pessoa marcada pela dificuldade de narrar e por uma postura de adesão à sua matéria que, adquirindo concretude nos textos, precisa ser pensada em termos de alcance estético-ideológico.
\end{abstract}

Palavras-chave: Literatura brasileira. Guimarães Rosa. Momento de escritura. Voz narrativa. Deficiência representativa.

Abstract: The essay aims at unravelling the rise of a second "writing moment" in Guimarães Rosa's work, delineated by a group of texts published in periodicals between Sagarana (1946) and the books of 1956, Corpo de baile and Grande sertão: veredas. Through the analysis of an important letter of the author and one of the capital texts of the period, "Com o vaqueiro Mariano", we intend to devise the guidelines of a new inflexion in Rosa's literature, characterized by the confrontation with the problems of "representative deficiency" inherent to Brazilian and international literary context and by the progressive constitution of a first person narrative voice marked by difficulties in narrating and by an adherent posture towards its matter that, as long as it gains concreteness in the texts, it must be thought in aesthetical and ideological terms.

Key-words: Brazilian Literature. Guimarães Rosa. Writing moment. Narrative voice. Representative deficiency.

\footnotetext{
${ }^{1} \mathrm{O}$ presente trabalho foi realizado com apoio do CNPq, Conselho Nacional de Desenvolvimento Científico e Tecnológico - Brasil.
} 



\section{Introdução}

A apreensão da obra de Guimarães Rosa a partir de "momentos de escritura", a despeito de inevitáveis imprecisões descritivas e de delimitação cronológica, parece ser um modo prolífico de se aproximar de determinados conjuntos de textos cuja partilha de formas, temas, espaços e impasses estéticos indicia um escopo de afinidades e problemas específicos de um período de escrita, podendo, por contraste ou consonância, alargar a compreensão de momentos precedentes ou posteriores e prover uma visão integrada da obra do escritor. Assim, desconsiderando os quatro contos de juventude, publicados no livro Antes das primeiras estórias (2011), pode-se sugerir que o primeiro momento da obra do escritor mineiro estaria localizado entre 1935 e 1937, período no qual escreve o livro de poemas Magma, vencedor do Concurso Literário da Academia Brasileira de Letras em 1936, mas publicado somente em 1997, e o livro Contos, posteriormente rebatizado Sezão, versão preliminar de Sagarana, que participa, ainda com o primeiro nome e sob o pseudônimo Viator, do Concurso Humberto de Campos da Livraria José Olympio Editora em 1938 obtendo o segundo lugar. A afinidade entre as duas obras já foi estudada por Maria Célia de Moraes Leonel (2000) que indicou a pertinência e interpenetração poética de imagens, temas e linguagem dos poemas do primeiro livro nos contos do segundo.

A publicação de Sagarana infundiu um espírito novo a uma forma tida como gasta e decadente, o conto regionalista. Para Candido (2002), Rosa foi capaz de inverter os sinais e converter em positivo o que nos outros escritores regionalistas era negativo, mas o engendramento de um "movimento interior" (p.186), capaz de animar toda uma região mais literária do que geográfica, depende de aspectos mais amplos. De fato, novas configurações históricas demandam novas formas artísticas, de modo que a essência contraideológica cara ao romance de 30 (BOSI, 2012), ver-se-á de certo modo esvaziada pelo malogro histórico de suas perspectivas e pela queda de interesse pela realidade brasileira, assim como da importância da prosa histórica e do ensaio sociológico, evidenciada na década de 1940. Para Bosi (2012), tais fatos fomentaram a produção de uma arte literária de maior transfiguração estética, algo evidente na prosa de "tensão transfigurada" (p.419) de Clarice Lispector - voltada para a história individual - e de Guimarães Rosa que, partindo das fontes da história coletiva, reinsere-as em formas modernas, revitalizando, assim, a possibilidade de uma épica do sertão (p.421); escritores cuja prosa está muito mais próxima do poético do que a dos prosadores de 30.

Como observa João Cabral de Melo Neto em "Esboço de panorama" (1998), há uma predominância do poético a partir dos anos 1940, mesmo fora do verso, o que revela a busca pelo "arredondamento lírico nas arestas agudas e violentas" (p.86) de uma então literatura de combate e denúncia bem como o anseio por "sobrerealidades" (p.86) construídas através de intensas pesquisas de linguagem. Em certo sentido, a necessidade de analisar e documentar cede lugar a uma "vontade-de-estilo que os impele à produção de objetos de linguagem a que buscam dar a maior autonomia possível" (BOSI, 2012, p.421) e a um potencial criador que anima por dentro as obras e exige novos modos de enfrentar a palavra e o fazer ficcional (p.420). Curiosamente, em Rosa haverá uma recrudescência da necessidade de analisar e documentar, direcionada para um melhor conhecimento de sua matéria narrável, mas sempre transfigurada pela linguagem, ou, posto de outro modo, "O aproveitamento literário do material observado na vida sertaneja se dá de 'dentro para fora', no espírito mais que na forma" (CANDIDO, 2002, p.141).

A escolha de uma forma específica, o conto regionalista, traz em seu bojo os ecos de sua presença na tradição literária brasileira bem como suas limitações formais e ideológicas. A priori, tal forma procura dar voz aos que não a tem e tal anseio advém de uma fratura específica na vida social: a inexistência ou impossibilidade do diálogo 
interclasses (BOLLE, 2004). Tendo suas origens no romantismo brasileiro, o conto regionalista desempenha, a seu modo, uma função semelhante à do romance enquanto instrumento de descoberta e interpretação do país (CANDIDO, 2012). Seu entrave maior, contudo, estava em sua "deficiência representativa" no que concerne à construção da voz do personagem rústico. A cisão entre o estilo culto da voz narrativa e uma variedade pitoresca de linguagem por parte do povo, como em Coelho Neto - "Não repetiremos o coelhonetismo", dirá Rosa em carta comentada no item 2 - produzia certos pontos de vista "esquizofrênicos" (CANDIDO, 2002, p.88) e tal modelo foi superado, em grande parte, com a possibilidade da interlocução "em presença" elaborada por Simões Lopes Neto (VASCONCELOS, 2008, p.383), que procurava preservar, pela linguagem, um modo de vida específico. A partir do legado do escritor gaúcho, Rosa irá aprofundar tal achado formal, culminando no monólogo dialógico estruturante de Grande sertão: veredas que expõe não só o problema da convivência tensa e dual característica da cultura brasileira, mas incrusta na própria forma em diálogo certo posicionamento estético e político.

A presença do monólogo dialógico enquanto operação formal estruturante é sentida em outros textos importantes do escritor, como "Meu tio o lauaratê", publicado em 1961 e incluído em Estas Estórias (1969), "O espelho", de Primeiras estórias (1962) e "Antiperipleia", de Tutameia (1967). Contudo, o surgimento de um ponto de vista em primeira pessoa com tal configuração parece ser um achado formal posterior ao primeiro livro. De fato, dos nove contos de Sagarana (1946), apenas "Corpo fechado", "Minha gente" e "São Marcos" adotam a perspectiva da primeira pessoa, sendo os dois últimos geralmente caracterizados pela crítica (Álvaro Lins, Antonio Candido, Paulo Rónai, entre outros) como textos menos bem realizados, opinião partilhada por Rosa sobre "Minha gente", mas não sobre "São Marcos", um de seus favoritos. Uma leitura do livro como um todo parece sugerir que Sagarana ainda não articula, enquanto constituinte temático, o impasse ostensivo da voz narrativa perante sua matéria - embora este já se faça presente nas frinchas da forma dos textos em primeira pessoa - e que se tornará uma espécie de mote central da produção rosiana publicada em periódicos entre 1947 e 1954, nosso objeto de interesse, culminando, sob perspectivas diversas, na estruturação da voz narrativa dos livros de 1956, Corpo de baile e Grande sertão: veredas. Há, em Sagarana, uma espécie de crença positiva nas possibilidades de figuração e uma liberdade de manejo que permite aos narradores intervir nos contos, inserir outros veios narrativos e clarificar pontos em busca de assegurar um sentido, como se nota na seguinte passagem de "A hora e vez de Augusto Matraga": "E assim se passaram pelo menos seis ou seis anos e meio, direitinho deste jeito, sem tirar nem por, sem mentira nenhuma, porque esta aqui é uma história inventada, não um caso acontecido, não senhor." (ROSA, 2001b, p.383)

A passagem para os livros de 1956 revela uma nova atitude diante da matéria narrada bem como uma mudança das próprias formas. Como diz Sandra Vasconcelos (2008), pensando em Corpo de baile, "Trata-se inegavelmente do mesmo universo, com seus bois, vaqueiros e fazendas de gado, mas o conto dramático que é a forma privilegiada do livro de estreia dá lugar a um tipo de narrativa mais visivelmente arcaica", marcada, sobretudo, pelo "modo de incorporação da oralidade" e pela constituição de uma voz narrativa que "adere ao ponto de vista do personagem, esfumando a separação entre essas duas instâncias e estabelecendo uma empatia e uma solidariedade de visão entre elas." (p.381)

Em outra passagem de seu texto, Vasconcelos contrapõe a composição de Sagarana, alicerçada em grande parte por "materiais organizados pelo trabalho da memória", à convivência direta enquanto "participante de um modo de vida" na viagem com a boiada de Manuelzão pelo sertão mineiro em 1952, experiência calcada no bojo de composição dos livros de 1956. Tal viagem permitiu a Rosa encontrar "soluções 
formais de alta potência literária para problemas como o da apropriação, por parte do narrador letrado, das peculiaridades da fala do homem rústico." (p.383). De fato, a memória em Sagarana não é apenas lembrança, mas imaginação criadora que define um modo específico de ver e sentir a matéria narrada. Neste sentido, torna-se muito interessante a lembrança de um verso do poema "Revolta", de Magma, que sem se concentrar em uma região específica, embora haja um destaque para a região mineira, cobre o Brasil como um todo: “minha pátria é a memória” (ROSA, 2005, p.136).

Enquanto constituinte formal, seja pelo monólogo dialógico, pela onisciência seletiva ou pelo discurso indireto livre, a formulação de tal ponto de vista internalizado não implica meramente a adequação a um conteúdo específico, no caso, às contradições do processo de modernização do país ou à falta de diálogo possível entre as classes. Em sentido mais amplo, ela traz em seu bojo um posicionamento político, que parece crer na possibilidade de integração dos excluídos e que, como lembra Vasconcelos, encontra ecos em um momento específico da história brasileira no qual havia uma crença generalizada na integração do país à modernidade plena: vistos retrospectivamente, os anos 1950 são tidos como "talvez o único período em que tivemos a chance de superar de vez a nossa condição de país periférico, miserável e dependente." (GAVA apud VASCONCELOS, 2008, p. 388).

Nesse sentido, a solução formal encontrada pelo escritor possui uma relação íntima com o seu contexto histórico: "em plena década de 1950, Rosa introjetou em sua obra a visão de um Brasil possível" pela forjadura de um ponto de vista que "longe de aprofundar as tensões, se constituía como a representação literária de vias ainda em aberto, de potencialidades da nossa ordem social." (p.391). Em um novo contexto, com a instauração da ditadura e o fechamento das "vias em aberto", tal postura afirmativa e integradora torna-se, com todas as suas possíveis contradições, irrepetível sob o risco de falsificação histórica (p.392).
Pensando com Eagleton, (2011, p.54), vemos que a escolha de uma forma é prenhe de ideologias que podem ser alteradas ou ressignifcadas até certo ponto a partir de certas condições históricas. Partindo do conto regionalista, de feição ideológica marcada e aprofundando o achado de Simões Lopes Neto, Rosa conseguiu forjar um ponto de vista orgânico à sua matéria narrativa, que falasse a partir de dentro, conferindo assim um grau de verossimilhança e coerência estrutural de grande força. Ao aproximar nosso escritor do mexicano Juan Rulfo, Davi Arrigucci Jr., destaca como decisiva a internalização do ponto de vista e sua contiguidade expressiva com os conteúdos a serem articulados:

O que mudou foi esta atitude que eles adotaram diante da matéria, por penetrarem nela de corpo e alma, por serem parte dela; [...] e essa visão interna, internalizada pelo narrador, é decisiva; ambos dependem da oralidade e da matriz do conto oral, que constitui o fundamento de nossa tradição épica, que acaba casada em liga orgânica com a tradição urbana do romance, por isso mesmo profundamente misturada e mudada entre nós, com relação ao que era enquanto matriz importada, para dar conta do que se tem de novidade para exprimir. (ARRIGUCCI, 2010, p.171)

De modo geral, a fortuna crítica de Rosa tem considerado tal conquista estética um fato positivo inconteste. Em um salto crítico corajoso, porém, Vasconcelos se pergunta em que medida tal recurso formal de identificação e mescla de vozes não acaba por, a contrapelo, silenciar aqueles a quem devia dar voz: "É possível, de fato, esse ponto de vista unificado, que reúne no texto literário aquilo que se separa na vida?" (2008, p.391). Na sequência de seu texto, a autora procura perscrutar como se deu, na literatura brasileira pós-Rosa, a formalização de tal questão, a ponto de termos uma voz narrativa internalizada não mais como resultado de apurada elaboração estética e mescla de vozes, mas como dado empírico, marcado pela "emergência de vozes sociais recalcadas, que, a partir de dentro de sua experiência de marginalização e exclusão, assumiram um lugar de fala" (p.394), ou, como formula Iná Camargo Costa, citada por Vasconcelos, "o objeto da pesquisa sociológica tornou-se sujeito da narrativa" (p.394), como no caso de Cidade de 
Deus (1997), de Paulo Lins, ou de Capão Pecado (2000), de Ferréz, obras analisadas por Vasconcelos.

Longe de tentar responder a questão formulada por Vasconcelos, que, como foi visto, incorpora uma outra ordem de problemas e requer uma concepção mais ampla das linhas de força da prosa brasileira atual, nossa contribuição se fará de modo retrospectivo, procurando flagrar como se dá o surgimento, na prosa de Guimarães Rosa, do ponto de vista interno à sua matéria.

\section{2 "Agora, porém, a hora é de combate, de ofensiva": balizas de uma poética em construção}

Em uma interessante carta de 11 de maio de 1947 para seu tio Vicente Guimarães, também escritor, Guimarães Rosa faz uma árdua crítica à literatura brasileira do período e esboça indícios claros de um programa literário:

A língua portuguesa, aqui no Brasil, está uma vergonha e uma miséria. [...] Empobrecimento de vocabulário, rigidez de fórmulas e formas, estratificação de lugares-comuns, como caroços num angu ralo, vulgaridade, falta do sentido de beleza, deficiência representativa. É preciso distendê-la, destorcê-la, obriga-la a fazer ginástica, desenvolver-lhe músculos. Dar-lhe precisão, exatidão, agudeza, plasticidade, calado, motores. E é preciso refundi-la no tacho, mexendo muitas horas. Derretê-la, e trabalha-la, em estado líquido e gasoso. (GUIMARÃES, 2006, p.138)

A carta articula um debate poderoso com a literatura e com a crítica literária produzida na época ${ }^{2}$, incluindo a emergência da geração de 45 e a derrocada do romance de 30 , e destaca uma série de procedimentos que, contrariamente às descrições de teor mais abstrato-filosófico que caracterizam suas poucas elaborações sobre o ofício literário expressas em outras cartas ou entrevistas, adquirem aqui um viés eminentemente material ao expressar a relação do escritor com a linguagem. É efetivamente através do fazer literário, do trabalho quase bruto

\footnotetext{
2 Em minha dissertação de mestrado, estudo em detalhes os possíveis diálogos da carta com a crítica literária nacional a partir de ensaios de Mário de Andrade, Graciliano Ramos, Álvaro Lins e Otto Maria Carpeaux publicados ao longo dos anos 1940 .
}

com a língua, que o escritor pode atingir seu anseio por embelezar e enriquecer o idioma enquanto único programa digno de um escritor (GUIMARÃES, 2006, p.135), não por vaidade estilística, mas para dar conta dos materiais a serem expressos. A "deficiência representativa", um evidente descompasso entre os meios de expressão e o material a ser expresso, torna-se uma questão crucial a ser combatida e da qual os textos produzidos individualmente e publicados em periódicos entre 1947 e 1954 esboçam inflexões e sugerem possibilidades e limites.

Este conjunto ${ }^{3}$, composto por vinte textos publicados em periódicos e culminando nos livros de 1956, Corpo de baile e Grande sertão: veredas, é marcado por uma indefinição de gênero aliada à constituição progressiva da voz narrativa em primeira pessoa que plasma, com dificuldade, espaços e sujeitos que não pertencem ao espaço de eleição do escritor, o sertão mineiro, e parece dar corpo à busca do autor pela constituição de um ponto de vista interno à matéria narrativa. Uma leitura destes textos revela não apenas uma dificuldade de narrar e certa precariedade de meios para enformar uma experiência específica, situada no presente, mas indicia a constituição de uma postura de adesão à matéria narrativa que assume o valor de resistência contraideológica que está no centro de uma nova inflexão da literatura rosiana.

Na mesma carta, Rosa destaca a imperícia criadora da literatura do período, feita a partir do aproveitamento "em décima ou vigésima mão, de reminiscências literárias, da literatice" ou mesmo do "folclore puro", não lapidado nem incorporado à obra de modo orgânico, resultando na constatação de que "não cuidamos da exatidão, da observação direta, do domínio dos temas, do estudo prévio, do

\footnotetext{
${ }^{3} \mathrm{O}$ conjunto é composto pelos seguintes textos, indicados de acordo com a cronologia das publicações: "São Marcos", "Histórias de fadas", "Sanga Puytã", "Com o vaqueiro Mariano" (publicado em três partes entre outubro de 1947 e março de 1948), "Cidade", "O mau humor de Wotan", "O lago do Itamaraty", "A senhora dos segredos", "Pé-duro, chapéu-decouro", "Cipango", "Teatrinho", "O homem de Santa Helena", "Terrae Vis", "Do diário de Paris" (publicado em duas partes em maio de 1953 e abril de 1954), "Fantasmas dos vivos", "Os doces", "A chegada de Subles", "Risada e meia", "Aquário (Nápoles)", "Uns índios - sua fala".
} 
planejamento, da construção literária." (p.138). Ao apontar o que falta àquela literatura e se incluir pronominalmente nos problemas levantados, o autor já indica os passos de seu projeto e termina clamando por atitudes práticas que incorporem elementos políticos: "Quem pode, deve preparar-se, armar-se, e lutar contra esse estado de coisas. É uma revolução branca, uma série de golpes de estado." (p.138)

Tal afirmação já organiza, em linhas gerais, uma espécie de itinerário poético que o autor passará a seguir nos textos do "segundo momento de escritura" e, mais do que isso, indica que tal fato se dá não por mera contingência, mas como aspecto volitivo, uma efetiva necessidade de conhecer melhor seu espaço de eleição a partir da "observação direta", do "planejamento" e "estudo prévio" dos temas, culminando, por fim, na ideia de "construção literária" (p.134). Uma visita ao Fundo João Guimarães Rosa (IEB-USP) permite constatar a quantidade de material utilizado para tal fim, incluindo cadernetas utilizadas in loco, cadernos de estudos e a vastíssima série Estudos para Obra que contém desde listas de palavras a esboços de textos maiores.

Para Rosa, a ênfase na ideia de arte como construção e chamada a combater um dado estado de coisas não é um fato concebido aprioristicamente, mas uma exigência do próprio tempo histórico:

Agora, porém, a hora é de combate, de ofensiva. Tudo está mudando, seo Vicente. Não retornaremos ao verbalismo inflacionado e oco de Coelho Neto, não repetiremos o coelhonetismo [...] Não se trata de um movimento intencional, artificialmente concebido. É, apenas, a voz dos tempos. Você acha que é por coincidência pura e simples, ocasional, que estão surgindo por toda parte, autores novos, falando em outro tom, e que os velhos, os melhores deles, começam a querer mudar de trote e acertar passo? "Arte é artifício", brada Graciliano Ramos. (GUIMARÃES, 2006, p.134)

Recuperando a dimensão combativa da "série de golpes de estado", Rosa cita, com evidente aprovação, um trecho de carta endereçada a ele por Lauro Escorel, na qual o crítico vê na nova geração literária, capitaneada por Rosa, Clarice Lispector e João Cabral de Melo Neto a valorização de algo que permitirá a feitura de obras "realmente grandes e duradouras": o "sentido da forma artística" (GUIMARÂES, 2006, p.136). Entretanto, tal destaque formal não implica uma hermetização ou fetichização gratuita das palavras, mas sim uma apreensão de seu sentido de construção artística aliada à dimensão da tradição literária. Assim, em concordância com Rosa, o crítico indica ainda que um dos grandes motivos do empobrecimento da literatura brasileira daqueles dias seria, em certa medida, sua falta de senso histórico:

Essa gente precisava ler mais os antigos, como você observa com razão; o que faz da nossa literatura moderna, com as exceções gloriosas de um Mário, de um Drummond de Andrade ou um Bandeira, etc., uma coisa tão insatisfatória, é que a turma começa a ler os modernos e se esquece de tudo o que ficou atrás; é como se alguém quisesse começar pela jabuticaba, ignorando o mato, a flor, a folha, a árvore, as raízes... O que precisamos é começar pela raiz, para que a nossa literatura ganhe a seiva e o viço do estilo. (GUIMARÂES, 2006, p.136)

Qualquer concepção demasiado formalista que pudesse ser sugerida pelo primado da forma artística é relativizada pela necessidade de se conhecer a tradição não apenas enquanto mera sucessão de autores e obras, mas enquanto processo. As metáforas naturais ("começar pela jabuticaba, ignorando o mato, a flor, a folha, a árvore, as raízes"), embora aqui elaboradas por Escorel, são muito presentes na obra de Rosa e tem, ironicamente, um efeito desnaturalizador, pois indiciam, problematicamente, frinchas e rincões de uma apreensão demasiado rápida do objeto que não passe pelo trabalho artístico capaz de torná-lo orgânico ao texto, como se verá no comentário sobre "Com o vaqueiro Mariano".

Levando em conta que a escrita da carta foi suscitada por críticas do tio à "crônica-fantasia" "Histórias de fadas", então recém-publicada, cremos ser pertinente pensar que tais pressupostos, em especial a valorização do "sentido da forma artística" e a superação do problema da "deficiência representativa" pelo aprofundamento do conhecimento do escritor sobre sua matéria a partir de vivências efetivas das quais as viagens e os 
textos resultantes dão indícios concretos, parecem presidir a composição dos textos, mas não enquanto programa estético imposto de cima para baixo, e sim como confronto pertinente a problemas estéticos da ordem do dia. Neste sentido, há um interessante espelhamento entre a inabilidade representativa da literatura brasileira do período e uma crise de representação mais ampla desencadeada pela experiência da guerra europeia, perante a qual a arte não pode ser mais a mesma nem lançar mão impunemente de formas contínuas e de feição totalizante:

Com a nova definição de realidade como catástrofe, a representação, vista na sua forma tradicional, passou ela mesma, aos poucos, a ser tratada como impossível; o elemento universal da linguagem é posto em questão tanto quanto a possibilidade de uma intuição imediata da 'realidade.' (SELIGMANN-SILVA, 2000, p.75).

No entanto, o aspecto volitivo da busca do escritor encontra-se em constante tensão com as circunstâncias e a força referencial dos eventos narrados, exigindo a adoção de um posicionamento da voz narrativa perante os acontecimentos.

Compostos a partir de experiências individuais e, em grande parte, localizáveis biograficamente, torna-se uma questão hermenêutica crucial posicionar os textos rosianos em seu "momento de escritura", gesto crítico que lhes confere novas tonalidades e Ihes permite prenunciar conquistas futuras ao invés de simplesmente repisá-las aparentemente sem o mesmo viço de antes, como poderia parecer em uma leitura que valorizasse apenas a data de publicação dos livros. Mais do que isso, sua apreensão individualizada, enquanto textos que não pertencem a um projeto de livro específico, mas compostos como "textos de circunstância" e que são veiculados em um suporte "circunstancial" como o jornal, é de considerável importância para compreender a própria instabilidade de gênero que marca este momento de escritura.

O conceito de "circunstância" pode ser mais bem entendido a partir das elaborações de Pedrag Matvejevitch (1971) e Jean Starobinski (2000). Das classificações que Matvejevitch estabelece, interessa-nos de perto a noção de que a poesia (e a obra de arte em geral) de circunstância pode ser feita em relação (par rapport) aos fatos relevantes da exterioridade, pensada não mais como ordem histórica, mas sim poética, i.e., que incorpora as modalidades do trabalho criador individual, desvelando, assim, os diferentes graus de implicação do eu naquilo que é dito (1971, p.178). Já Starobinski elabora seu conceito de "poésie de l'événement' a partir da emergência de uma nova poesia nascida do acontecimento (2000, p.11) na qual, em face de um contexto marcado pelo jogo de potências que nos afrontam em situação de catástrofe, o poeta não pode mais se portar como mero espectador da história, sendo imprescindível o exercício da palavra assim como a escolha de um lugar de fala. (p.14). Neste sentido, é prerrogativa do artista conferir ao evento histórico a qualidade de evento interior, na medida em que a verdadeira poesia, marcada pela "urgência do instante" (p.18), interioriza a arte e se converte, pelo canto, no "intermediário admirável pelo qual a circunstância encontra a eternidade" (p.9).

Premido por um Zeitgeist semelhante, fomentado especialmente por sua experiência na guerra europeia e a reverberação autoritária desta no Estado Novo brasileiro, o segundo momento de escritura rosiano é marcado pela feitura de textos cujo caráter circunstancial pode ser entendido como a adoção, consciente de seus limites, de um lugar de fala perante a matéria representada. Resta, contudo, a recorrente questão da emancipação ou dependência da arte em relação aos eventos a que dá forma. É evidente que uma das grandes possibilidades do fazer artístico é a de, pela coesão da fatura, falar intensamente de coisas que não se experimentou, recuperando a distinção aristotélica entre o poeta e o historiador. Em grande medida, foi pela organização do trabalho da memória enquanto força criadora - "minha pátria é a memória" - que as narrativas de Sagarana foram compostas, sem capitanear diante pujança referencial do seu conteúdo em prol de uma criação mais ampla e que se processa pela linguagem. Daí a composição de uma região mais literária do que geográfica, tornada 
verossímil não pelo pormenor descritivo, mas pelo trabalho linguístico. (CANDIDO, 2002: p.188)

Paradoxalmente, as narrativas do segundo momento de escritura deveriam, pelo primado da experiência direta, ser mais fluidas e mais formalmente distintas em termos de forma narrativa. No entanto, a experiência por si só não produz grande arte e é justamente em seu caráter circunstancial, associado à "variedade irredutível dos acontecimentos" (MATVEJEVITCH, 1971, p.177) e à implicação da voz narrativa nos eventos narrados que reside o principal interesse destes textos. É a formulação de um ponto de vista em primeira pessoa que percebe os problemas de representação, a dificuldade de enformar sua matéria e as tensões referentes à transmissibilidade da experiência que os textos procuram transfigurar, culminando em uma indeterminação de formas constitutiva à sua dimensão circunstancial.

A própria feitura e composição destes textos enquanto vivência efetiva a que se procura dar forma artística vai de encontro ao problema constatado por Walter Benjamin sobre o empobrecimento das ações da experiência (1985) e à impossibilidade da representação em tempos de catástrofe. Assim, dar forma estética ao que se viveu e/ou testemunhou criar uma ponte entre a Erlebnis e a Erfahrung (GAGNEBIN, 1985) - diante do horror totalitário, torna-se uma atitude ética cujo alicerce central está na percepção da experiência da Guerra enquanto uma circunstância perante a qual cabe aos homens agir e aos artistas assumir seu lugar de fala (MOURA, 2016, p.10).

Nesse sentido, a escritura do Diário de Hamburgo (ou Diário de Guerra) durante os primeiros anos da Segunda Guerra, no qual Rosa anota desde experiências rotineiras como encontros e conversas, pequenas composições literárias, notas de leitura e a ocorrência de bombardeios, registrados de forma quase obsessiva, adquire, como primeira manifestação mais assídua do uso da primeira pessoa, certo caráter fundador do momento de escritura que nos interessa. Se, como lembra Eksteins, "Quando o passado sumiu pelo ralo, o eu tornou-se de importância capital." (1991, p.271), não é de se estranhar que o ponto de vista adotado nos chamados contos alemães, "O mau humor de Wotan", "A Senhora dos Segredos" e "A velha", seja o da primeira pessoa. No entanto, diferentemente do Diário, tais textos parecem ter sido produzidos no Brasil e, em especial em "O mau humor de Wotan", nota-se um posicionamento de clara resistência diante da barbárie nazista que comparece mais matizado e entrançado nas anotações do Diário, em que, premido por um "antagonismo constitutivo" (GINZBURG, 2010, p.98) - espécie de violência de mão dupla entre as manifestações do nazismo que começam a amargar a paixão que nutria pela cultura alemã e os bombardeios dos aliados, que atingiram um dos locais onde residia e o consulado onde trabalhava - o escritor não aponta indícios de um posicionamento inequívoco, procurando não idealizar nenhum dos lados, ciente de que "não há forças históricas próximas destituídas de violência" (p.98).

Perante a situação de guerra, que esfarelou as certezas e qualquer crença no progresso histórico, há uma atitude específica, na escrita do diário, que se sobressai:

Em meio a um campo de destruição intensa, há algo que precisa ser construído. O 'Diário', ele próprio. E com ele, o sujeito, a linguagem. O 'Diário' é evidência, por sua existência, de uma valorização, por parte de Rosa, do trabalho de enunciação, a insistência em não calar, em continuar escrevendo mesmo num ambiente extremamente hostil à comunicação. (GINZBURG, 2010, p.104)

A dimensão de resistência ética, composta pela adoção de uma voz narrativa em primeira pessoa consciente de seus limites e por uma postura de adesão à matéria que procura plasmar esteticamente, não é exclusividade dos textos alemães, mas uma espécie de tônica dominante de todo um período de escrita que cabe esmiuçar melhor a partir de um de seus textos-chave, o "contoentrevista" "Com o vaqueiro Mariano".

\section{Com o vaqueiro: o diálogo (im)possível}

Ao retornar ao Brasil após a experiência alemã (1938-42) e o período em Bogotá (1943-44), 
Rosa dará início às suas viagens pelo interior do Brasil, passando pelo sertão mineiro em 1945, na chamada "Grande excursão a Minas"; pelo Pantanal em 1947; e, novamente, pelo sertão mineiro e baiano em 1952. Destas últimas, resultarão dois textos, "Uma estória de amor", novela de Corpo de baile que tem como personagem central 0 vaqueiro Manuelzão, e "Pé-duro, chapéu-de-couro", uma espécie de épica ensaística sobre um encontro de vaqueiros ocorrido em Caldas do Cipó (BA) 1952. A viagem ao Pantanal, no entanto, parece ser a que mais rendeu textos: "Sanga Puytã", "Com o vaqueiro Mariano", "Cipango", "Ao Pantanal” e, possivelmente, teve alguma influência na composição de "Meu tio o lauaretê".

Dentre este conjunto, excluindo o último, "Com o vaqueiro Mariano" ${ }^{4}$ é sem dúvida o mais significativo e apresenta pela primeira vez na obra de Rosa indícios da construção da técnica do monólogo dialógico em estado embrionário. No texto, posteriormente transformado em livro de edição limitada em 1952, com consideráveis alterações, o autor não procura "gravar" a "fala" do vaqueiro e transcrevê-la tal qual - o que seria o procedimento padrão da literatura regionalista, que fotografa o exótico e o expõe a olhos capazes de contemplá-lo apenas como diferença, e não como alteridade, permanecendo a percepção no nível do anedótico e do pitoresco -, mas antes permite que o narrador e seu objeto-sujeito sejam produzidos pela narrativa, de modo que embora torne Mariano personagem de seu relato, o narrador não ousa dominá-lo enquanto objeto literário, penetrando em sua mente e tingindo seu discurso com o dele e vice-versa; pelo contrário, respeita a referencialidade do personagem (dentro, é claro, do jogo ficcional), expressando-se este sempre em discurso direto. As manifestações do narrador, com exceção de uma única linha final, são sempre em discurso indireto, de modo que, em termos formais ostensivos, o diálogo não se dá.

\footnotetext{
4 Publicado originalmente no Correio da Manhã (RJ) em 26/10/1947, 22/02/1948 e 07/03/1948. As citações, quando não houver outra indicação, foram retiradas de um exemplar do periódico que integra o Fundo João Guimarães Rosa (IEBUSP), documento JGR-R2,235.
}

Chamado de "conto-retrato" ou "reportagem poética" e dividido em três partes, o texto principia pela descrição do entrevistado e as circunstâncias de seu encontro com o narrador, iniciado por longa conversa noite adentro no mês de julho na Fazenda Firme, Nhecolândia, Pantanal, por meio da qual o vaqueiro vai saciando gradualmente o anseio do narrador por saber mais sobre "a alma dos bois". A habilidade do contador, "homem-de-ação posto em tarefa meditativa", dotado de "Umas palavras intensas, diferentes, abrem a vastidão de espaços onde o real se faz fábula", garante-lhe a atenção do narrador, que presencia o trânsito infindável dos rebanhos entre as sombras, sua e do vaqueiro, "mudamente amigas, grandes", projetadas na parede, e que se deleita com palavras e imagens detentoras da "verdade estranha das coisas supostas".

As partes II e III correspondem às lidas cotidianas de Mariano e à experiência vivenciada pelo narrador ao participar das mesmas, embora principie pelo narrador vagando sozinho pelo novo ambiente e procurando absorvê-lo esteticamente. Nestas partes, a voz de Mariano aparece um pouco menos, predominando as impressões do narrador. As intervenções de Mariano, de modo geral, caracterizam-se pelo teor prático e quase proverbial: "Tem boi que pode tomar ódio a uma pessoa" ou ainda "Aqui, o gado é que cria a gente". Após cavalgar com o vaqueiro e ser salvo pelo mesmo de um ataque de boi bravo, o narrador contempla ao lado dele a intrepidez de um casal de pássaros na defesa de seu ninho, capazes de fazer uma boiada "destorcer p'ra um lado e quebrar rumo" (ROSA, 2006, p.154), culminando em uma compreensão mútua pelos homens, a partir de uma experiência compartilhada, sobre o que acabou de ser visto: "- É, sim senhor. O amor é assim."(p.154) .

O parágrafo inicial indicia todo um programa estético por parte de Rosa em forte oposição ao regionalismo do século XIX que heroicizava, em moldes burgueses, a figura do vaqueiro:

Em julho, na Nhecolândia, Pantanal de Mato Grosso, me encontrei com um vaqueiro que reunia em si, em qualidade e cor, quase tudo 
- que a literatura empresta esparso aos vaqueiros principais. Típico, e não um herói, nenhum. Era tão de-carne-em-osso, que nele não poderia empessoar-se o cediço e fácil da pequena lenda. Apenas um profissional esportista; um técnico, amoroso de sua oficina. Mas denso, presente, almado, bomcondutor de sentimentos, crepitante de calor humano, governador de si mesmo; e inteligente. Essa pessoa, este homem, é o vaqueiro José Mariano da Silva, meu amigo.

Caracterizado como "denso, presente, almado", Mariano é capaz de articular suas experiências com tranquilidade, sendo "bom-condutor de sentimentos" e "governador de si mesmo". Emanando um "sentido de segurança, uma espécie tranquila de força", o vaqueiro conta "no de leve, sem por sentido", deixando a interpretação por conta do ouvinte que, como se verá, encontra sérias dificuldades em mediar o legado problemático de Mariano e a experiência do leitor.

O conceito de típico - "Típico, e não um herói, nenhum" -, ainda em que contexto diverso, pode ser aproximado às reflexões de Lukács tal como articuladas por Eagleton:

Um personagem "típico" ou "representativo" encarna forças históricas sem deixar, por causa disso, de ser individualizado de maneira rica; e para um escritor dramatizar essas forças históricas ele deve, para Lukács, ser "progressista" em sua arte. Toda grande arte é socialmente progressista no sentido de que, não importa qual seja a filiação política consciente do autor (e, no caso de Scott e Balzac, ela é abertamente reacionária), ela torna concreta as forças "histórico-universais" de uma época, forças que formam a base para a mudança e o crescimento, revelando seu potencial de desenvolvimento em seu mais alto grau de complexidade. (2011, p.58)

Neste sentido, a figuração de Mariano feita por Rosa, ainda que ligada ao vaqueiro individualizado, extravasa sua referência, tocando em dimensões mais amplas de representação. Se, por um lado, o conto pode ser entendido como uma espécie de estudo de um vaqueiro singular, emoldurado, típico estudo que terá sua contraparte em "Pé-duro, Chapéu-de-couro", de 1952, que procura pensar os vaqueiros quase que em termos plurais de "classe", ele já elabora, pela dimensão singular, o problema central da falta de entendimento e diálogo entre as classes, central em Grande sertão: veredas (BOLLE, 2004: p.385) e esboça, através da sequência de falas de Mariano em discurso direto, sem interrupção do narrador e nas quais se percebe respostas a perguntas não enunciadas, a construção da técnica do monólogo dialógico:

- ... Medo? se tive. Meu corpo quis ficar pequetitinho... Dei força pra me levantar inteiro d'água, morrendo por voar, que como pássaro... Se tivesse arma-de-fogo na mão, tinha baleado minha cabeça. Parei bobo, estuporado, e fiquei esperando em todas as minhas partes a dor d'elas me comendo... O senhor já viu piranha?

- ... Não. O outro boi e as vacas, que iam nadando perto, não se importaram, navegando num sossego, sem nenhuma notícia do que estava doendo com o desgraçado...

Ponto culminante da primeira parte e, possivelmente, de todo o texto, o parágrafo a seguir, colocado entre duas falas do vaqueiro, mas não dirigido a ele, é um comentário do narrador que confessa a precariedade de seus meios para captar as passagens "lavradas" pelo vaqueiro:

Te aprendo e aplaudo, José Mariano, meu companheiro, meu parceiro: ninguém contaria melhor. Muito, porém, por mais que faças, por nenhum meio, não poderás transmitir-me. Das tuas próprias passagens do que vamos lavrando, no desmedido vivor da natureza, para a retardar, colher, distilar, possuir. Como o que a laranjeira não ensina ao limoeiro, e que um boi não consegue dizer a outro boi. Alguma coisa que é química e é só tua, algo que acende melhor teu fundo dos olhos, que dá mais trunfo à sua voz e tento às tuas mãos. Em Terra Indoméstica, te aqui puseram, de onde um dia te extrairão, saturado e completo, como um rolo de filmes a ser revelado. Professo, por mim, que um não venceria compor, em personagem, o vaqueiro moldado e autêntico que tu és. Mas, as histórias não se separam do contador, mais do que se desprende de uma lâmpada sua luz. Conta e vai. Vamos transferir outros rebanhos, para as invernadas do simbólico.

Dada a impossibilidade de compor Mariano em personagem, resta ao narrador dar espaço para as falas do vaqueiro e registrar o impasse na transmissibilidade das experiências narradas por ele. A íntima imbricação entre o contador e a matéria de seus causos - "as histórias não se separam do contador, mais do que se desprende de uma lâmpada sua luz" - impede qualquer paráfrase ou remodelagem por parte do narrador. Neste sentido, o próximo passo do escritor em textos futuros será o apagamento virtual do ouvinte e seus comentários, 
entregando a voz narrativa ao personagem de modo integral, convertendo o texto como um todo em uma fala.

Lembremos, contudo, que o decisivo no desenvolvimento da técnica esboçada neste conto não é o monólogo em si, mas sim "a revolução social do ponto de vista, que permite, entre outras coisas, também o uso do monólogo: é a penetração na matéria, o que, na verdade, implica algo maior: a experiência histórica incorporada como visão de realidade." (ARRIGUCCI, 2010, p.173). Assim, a própria figuração do impasse do narrador perante sua matéria enquanto confronto com os problemas da "deficiência representativa", pela exposição de sua falibilidade, já é, em si mesma, uma conquista de linguagem: ao fazer uso de símiles partícipes do universo simbólico e cultural daquele a quem se procura dar voz - "Como o que a laranjeira não ensina ao limoeiro, e que um boi não consegue dizer a outro boi" - tal formulação sugere uma possibilidade de integração, problemática e pela linguagem, do narrador culto e letrado no universo da cultura oral e no mundo de experiências do vaqueiro. Há de se notar, todavia, que o impasse enunciado comparece na própria estruturação figurativa do trecho, que compreende outros dois símiles mais próximos do escopo de referências do narrador citadino: "como um rolo de filmes a ser revelado" e "mais do que se desprende de uma lâmpada sua luz". Assim, a forjadura de uma linguagem comum esbarra, neste primeiro momento, na própria constituição do acervo de recursos estilísticos do narrador, que, em outros textos, acabará por decantá-los e fundi-los em uma linguagem misturada capaz de dar conta daquilo que se almeja representar.

Creio que tal hipótese se confirma na própria reescrita do trecho, feita para sua edição em livro em $1952^{5}$ - e que se mantém, com poucas alterações, na versão presente em Estas Estórias (1969) - em que Rosa manteve os primeiros símiles, mas

\footnotetext{
5 ROSA, João Guimarães. Com o vaqueiro Mariano. Rio de Janeiro: Edições Hipocampo, 1952. Tiragem limitada de 116 exemplares. Ilustração de Darel Valença Lins. Consultei o exemplar da biblioteca de Rosa no IEB-USP.
}

eliminou os últimos. A reescritura do conto revela uma visão mais sintética na qual a indissociabilidade entre narrador e matéria narrada ganha uma dimensão especular em que as estórias contadas acabam por performá-lo:

Te aprendo ao fácil, Zé Mariano, maior vaqueiro, sob vez de contador. A verdadeira parte, por quanto tenhas, das tuas passagens, por nenhum modo poderás transmitir-me. $\mathrm{O}$ que a laranjeira não ensina ao limoeiro e que um boi não consegue dizer a outro boi. Ipso o que acende melhor teus olhos, que dá trunfo à tua voz e tento às tuas mãos. Também as estórias não se desprendem apenas do narrador, sim o performam; narrar é resistir. (ROSA, 1952)

Em um rearranjo mais hermético, condensado e simbólico, que parece ser uma característica da escrita rosiana ao longo do tempo, em especial na reescritura dos textos do período 1947-54, Rosa indica 0 caráter formativo das narrativas na composição do vaqueiro narrador, cujo ato narrativo é percebido como um ato de resistência perante o esfacelamento das tradições e de seu modo de vida específico. É preciso notar ainda que o acréscimo da palavra "Entremeio" ao título do conto na versão presente em Estas estórias é bastante significativo: além de se referir à posição do conto no livro, à sua natureza híbrida de reportagem poética e ao papel desempenhado pelo narrador (uma espécie de dupla mediação reforçada pelo acoplamento de 'entre' com 'meio') "entremeio" também se refere ao "apalpo ('depósito gorduroso') dos bovinos, esp. das vacas, em forma de cordão, situado na região perineal" (Houaiss), destacando a imanência entre a matéria por representar e a forjadura literária da forma.

Por fim, há que se destacar que o esforço de dar uma forma una, totalizante em certa medida, por meio da composição de um "conto-retrato", carrega em si mesmo um pressuposto ideológico. Como nos lembra com grande acuidade Ángel Rama, (2001, p.272), pensando em nosso texto, assim como em Grande sertão: veredas, "a resistência da cultura que recebe a modernização se apoia, mais ainda do que na sobrevivência do padrão léxico, em um nível superior dos sistemas narrativos nos quais podemos vislumbrar um homólogo das formas de pensar." Ao tentar dar forma ao material coletado do personagem 
rústico, o narrador produz um "esforço para construir uma totalidade, dentro da qual se recuperam as formas desconexas e dispersivas da narração rural, mas ajustadas a uma unificação que já procede do impacto modernizador." (p.272). Parece certo que a própria forma fendida entre discurso indireto e direto, narrador e vaqueiro, junto com a precariedade dos meios de figuração e transmissibilidade da experiência, já apontam para o idealismo de tal premissa. No fim, o que se salva é o ato narrativo como ato cognoscitivo, capaz de resistir contra o silêncio problemático e ideológico que separa tais universos culturais e de, gradualmente, pela construção de uma linguagem comum, converter o logos partido em diálogo: "- Melhor, sim, Mariano".

\section{Referências}

ARRIGUCCI Jr, Davi. Fala sobre Rulfo. In: 0 Guardador de Segredos: ensaios. São Paulo: Companhia das Letras, 2010, p.168-182

BENJAMIN, Walter. Magia e técnica, arte e política Ensaios sobre literatura e história da cultura. Traduzido por Sérgio Paulo Rouanet. São Paulo: Brasiliense, 1985

BOLLE, Willi. grandesertão.br. o romance de formação do Brasil. São Paulo: Editora 34, 2004

BOSI, Alfredo. História concisa da literatura brasileira. 48ํㅡㄹ ed. São Paulo: Cultrix, 2012.

CANDIDO, Antonio. A nova narrativa. In: A educação pela noite e outros ensaios. São Paulo: Ática, 1989

"A literatura e a formação do homem"; "Sagarana" e "No Grande sertão". In: Textos de intervenção. São Paulo: Editora 34, 2002

Formação da Literatura Brasileira: momentos decisivos 1750-1880. 13 ${ }^{a}$ edição. Rio de Janeiro: Ouro sobre Azul, 2012

EAGLETON, Terry. Marxismo e crítica literária. São Paulo: Editora Unesp, 2011

EKSTEINS, Modris. A sagração da primavera: a Grande Guerra e o nascimento da era moderna. São Paulo: Rocco, 1991
FUNDO JOÃO GUIMARÃES ROSA. Arquivo do Instituto de Estudos Brasileiros - USP.

GAGNEBIN, Jeanne Marie. Walter Benjamin ou a história aberta. In: BENJAMIN, Walter. Magia e técnica, arte e política - Ensaios sobre literatura e história da cultura. São Paulo: Brasiliense, 1985, p. 7-19

GINZBURG, Jaime. Notas sobre o "Diário de Guerra" de João Guimarães Rosa. Aletria (UFMG), Belo Horizonte, v. 20, n.2, p. 95-107, 2010.

GUIMARÃES, Vicente. Joãozito: a infância de João Guimarães Rosa. São Paulo: Panda Books, 2006

LEONEL, Maria Célia de Moraes. Guimarães Rosa: magma e gênese da obra. São Paulo: Editora Unesp, 2000

MATVEJEVITCH, Pedrag. La poésie de circonstance: étude des formes de l'engagement poétique. Paris: A.G.Nizet, 1971

MELO NETO, João Cabral. Prosa. Rio de Janeiro: Nova Fronteira, 1998

MOURA, MURILO MARCONDES. O mundo sitiado: a poesia brasileira e a Segunda Guerra Mundial. São Paulo: Editora 34, 2016

RAMA, ÁNGEL. Literatura e cultura na América Latina. Flávio Aguiar e Sandra G. T. Vasconcelos (orgs.), São Paulo: Edusp, 2001

ROSA, João Guimarães. Com o vaqueiro Mariano. Rio de Janeiro: Edições Hipocampo, 1952 2001

Ave, Palavra. Rio de Janeiro: Nova Fronteira, . Sagarana. Rio de Janeiro, Nova Fronteira, 2001. 2006.

Estas estórias. Rio de Janeiro, Nova Fronteira, Magma. Rio de Janeiro, Nova Fronteira, 2005.

SELIGMANN-SILVA, Márcio. A História como trauma. In: SELIGMANN-SILVA, Márcio \& NESTROVSKI, Arthur (org.). Catástrofe e representação. São Paulo: Escuta, 2000, p. 73-98

STAROBINSKI, Jean. La Poésie e la Guerre: Chroniques 1942-1944. Paris: Minizoé, 2000

VASCONCELOS, Sandra G. T. Vozes do centro e da periferia. In: Marli Fantini Scarpelli. (Org.). A poética migrante de Guimarães Rosa. 1a.ed. Belo Horizonte: Editora UFMG, 2008, v. 1, p. 380-399

\section{COMO CITAR ESSE ARTIGO}

VILHENA, Guilherme Mazzafera e Silva. Narrar é resistir: impasses de representação narrativa em João Guimarães Rosa no fim dos anos 1940. Signo, Santa Cruz do Sul, v. 42, n. 74, maio 2017. ISSN $1982-2014$. Disponível em: <https://online.unisc.br/seer/index.php/signo/article/view/8716>. Acesso em: doi: http://dx.doi.org/10.17058/signo.v42i74.8716. 